
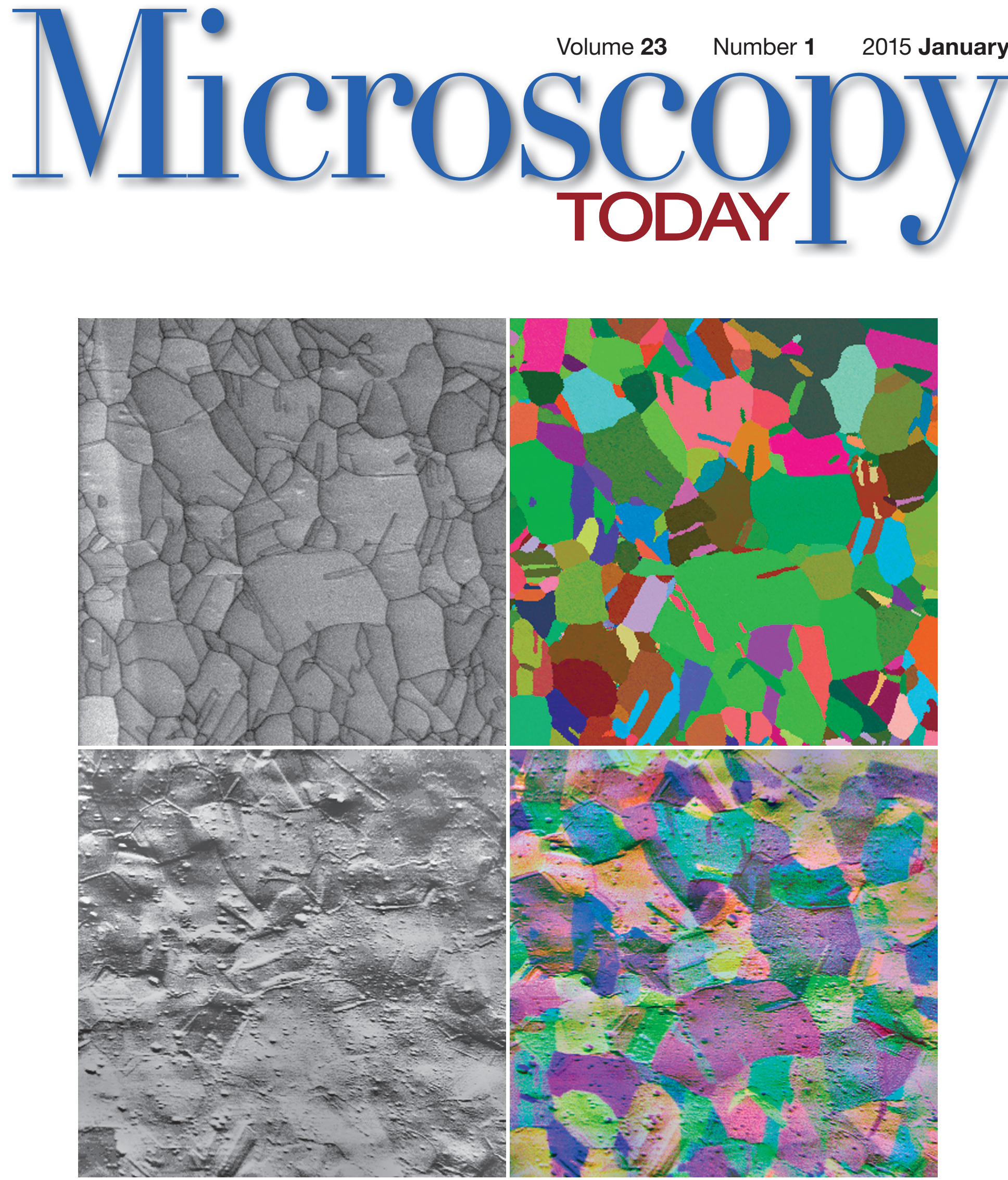


\section{HITACHI Inspire the Next}

\section{Expand Your Boundaries}

Discover the Nano-World with the Hitachi A Fyboos

\section{Vacuum ststem}

2. High-resolution observation of electromagnetic properties

- High témperature and cryogenic measurements

\section{In-situ Observation}

- In air or in solution

- Humidity control

- Temperature control

\section{Air Protection}

- SEM and ion milling compatible sample holder

Environmental-Control Atomic Force Microscope

\section{AFM5300E}

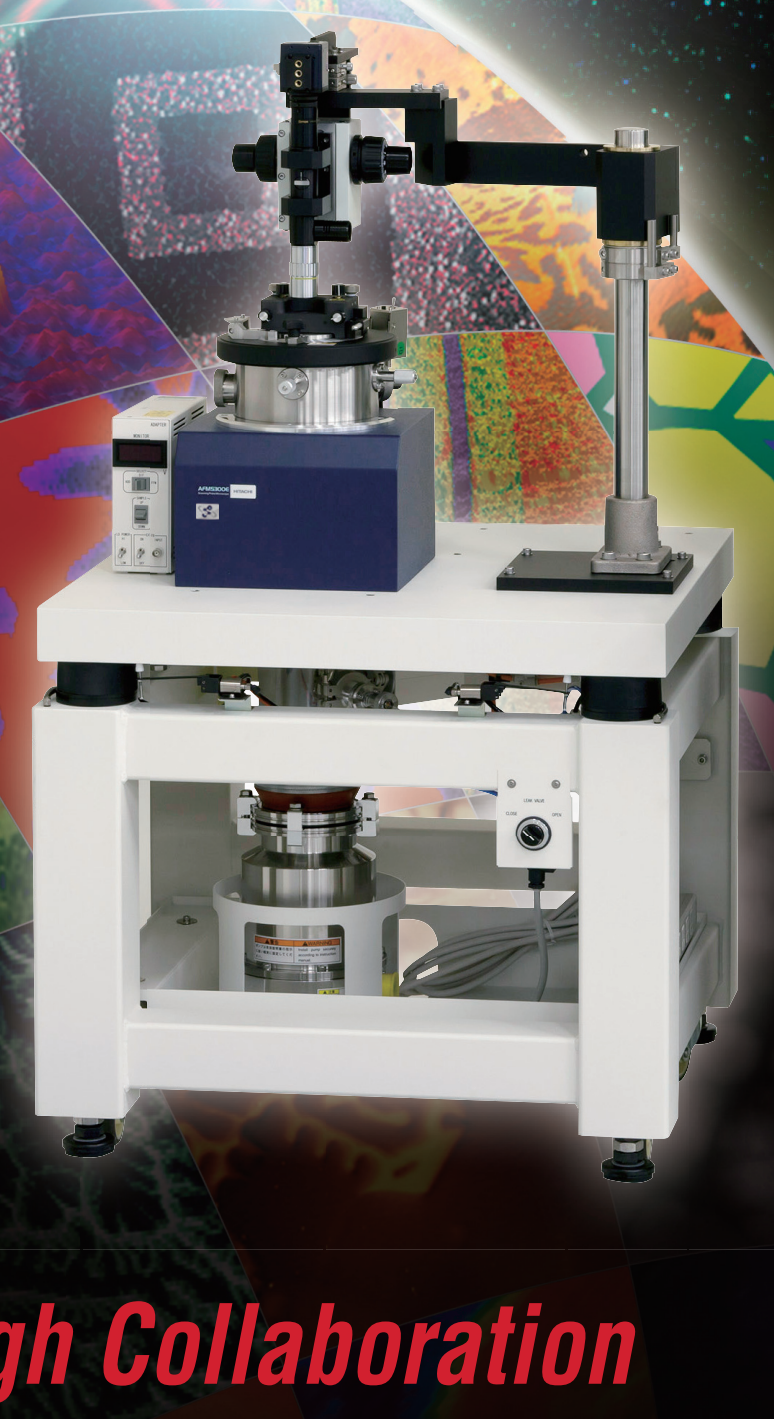

Hitachi High Technologies America, Inc.

www.hitachi-hta.com

Tel. 800-548-9001 
PAPER SUBMISSIONS: Open December 1, 2014

SUBMISSION DEADLINE: February 9, 2015

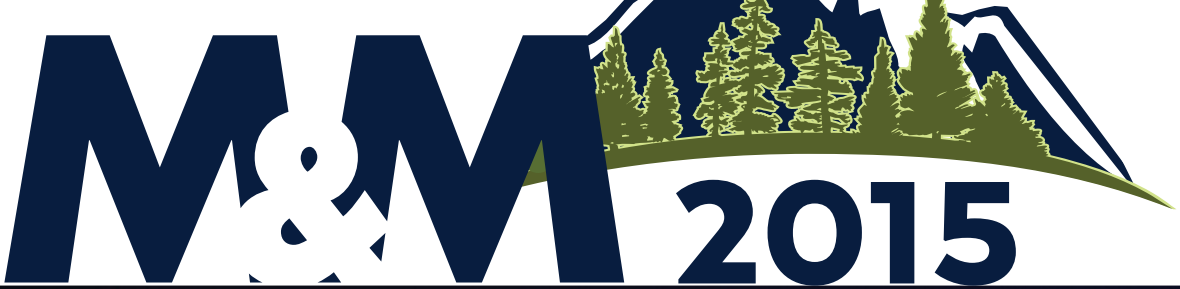

.

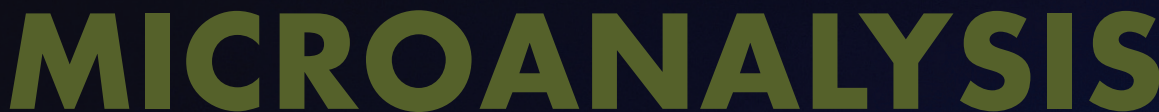
August 2-6. Partland, OR

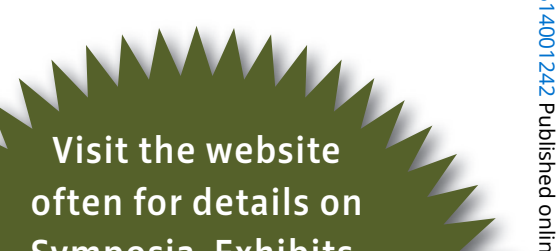

Symposia, Exhibits, Biological and Physical Sciences Tutorials, In-Week Intensive Workshops, Posters, Sunday Short Courses and Pre-Meeting Congress!

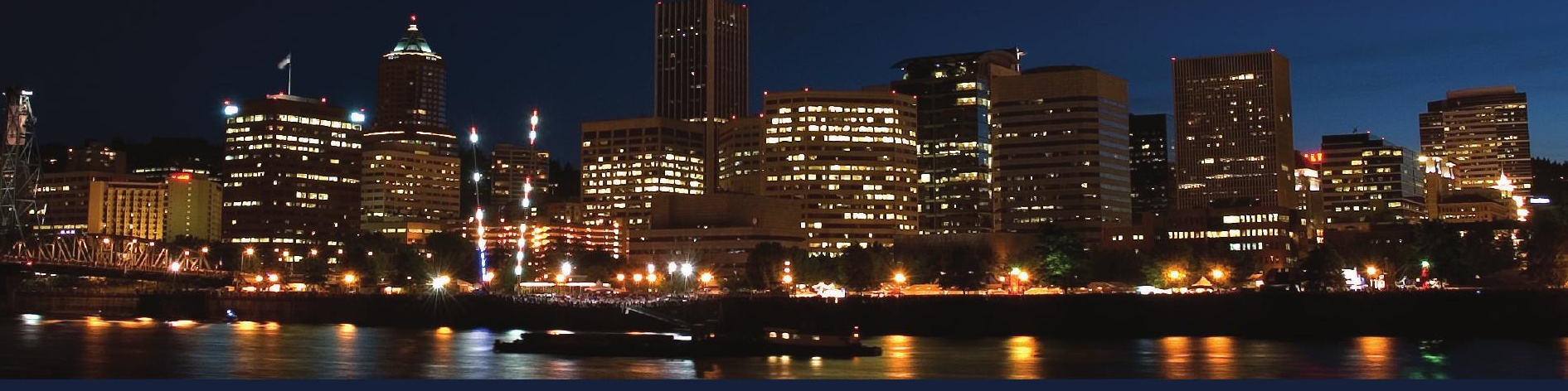

\section{http://microscopy.org/MandM/2015}
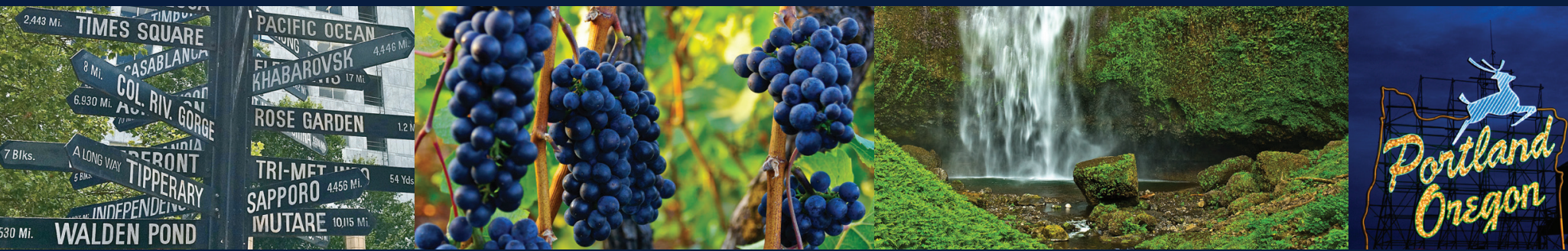

Program Information | Information for Students | Meeting Awards (apply when you submit your paper!) | Exhibitor List \& Floor Plan | Online Registration (opens February 2015) | Portland Hotel Information (reservations available February 2015)

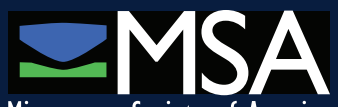

Microscopy Society of America

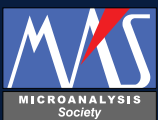



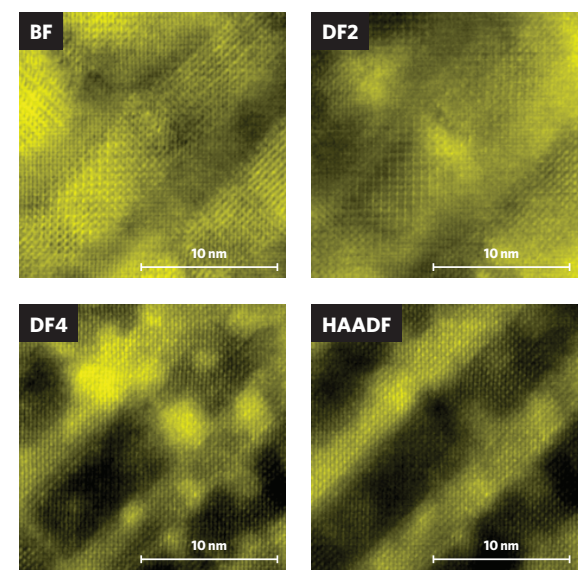

4 channel simultaneous HRSTEM imaging of $\mathrm{SrTiO}_{3}$ using 4 STEM detectors.

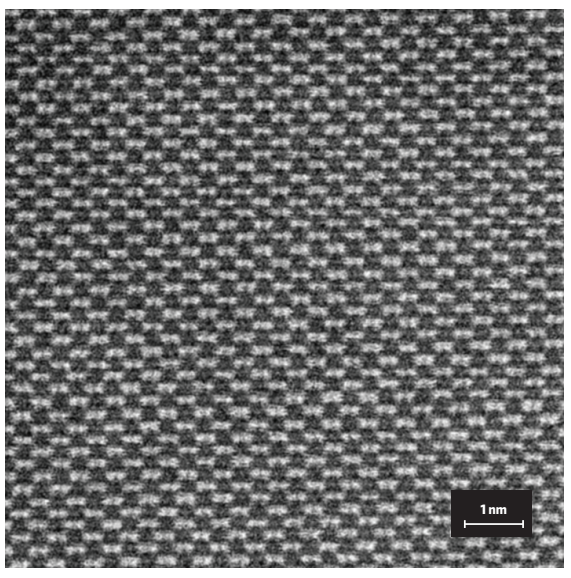

HRSTEM of Si (110) at 200kV.

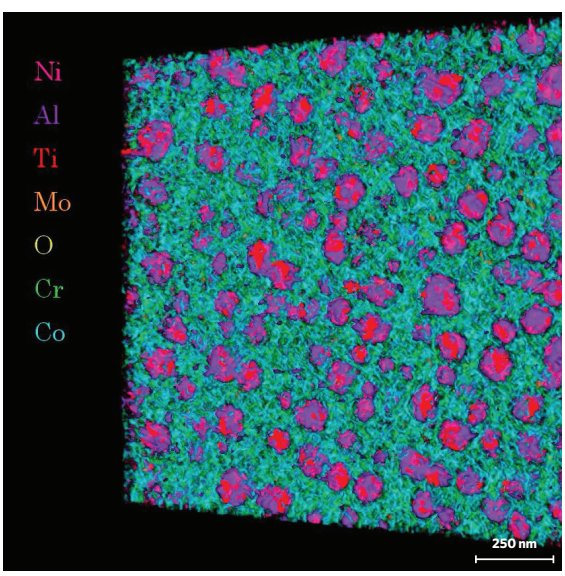

Combined 3D EDS map: Ni, Al, Ti, Mo, Cr, and Co.
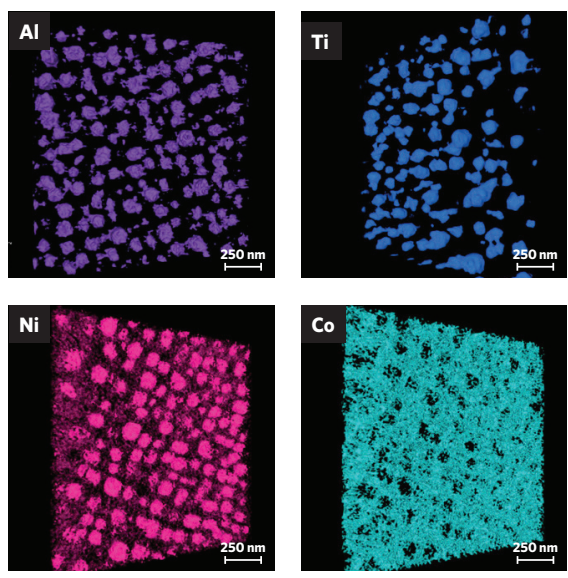

3D EDS maps at different angles.
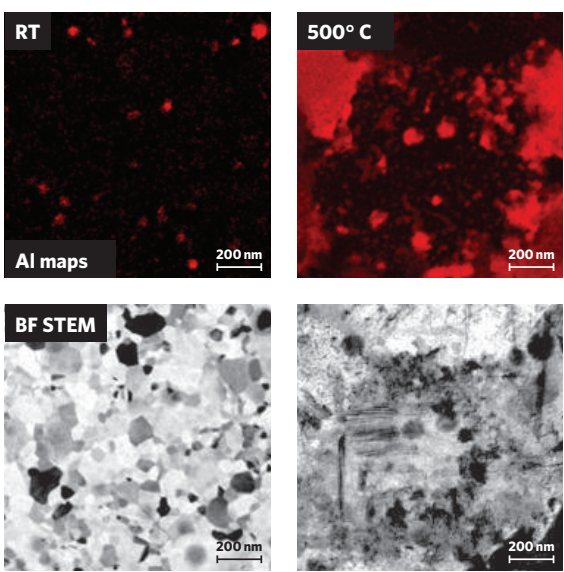

Temperature driven Al aggregation in solar cell. Sample courtesy of Dr. S. Kraschewski, U. Erlangen.

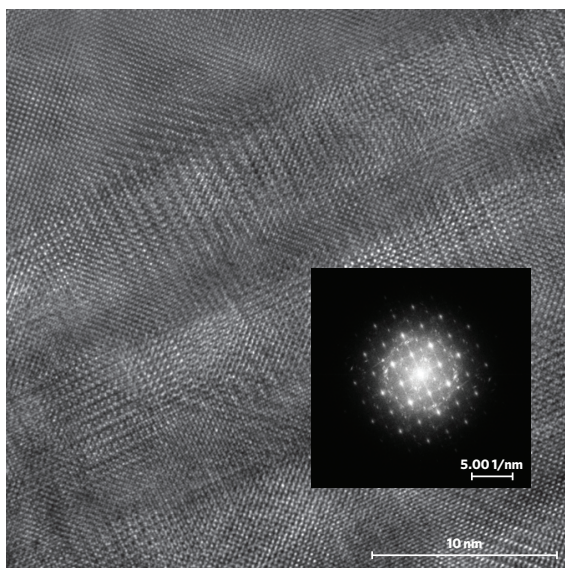

HRTEM image of $\mathrm{SrTiO}_{3}$ with Ceta $16 \mathrm{M}$ camera.

\section{Fast 2D \& 3D Imaging and Chemical Analysis}

\section{with Talos TEM}

Whether you work with metals, light elements, or nanoparticles from macro to atomic scales-Talos gives you insight into structure and composition for a complete understanding of material properties.

High speed 2D and 3D EDS analysis: Fast, multichannel, automated EDS acquisition and precise quantification to obtain multidimensional compositional maps.

Fast navigation and imaging: High throughput, high resolution uncorrected $\mathrm{S} / \mathrm{TEM}$ images - even for beam sensitive and challenging materials.

Space to do more: FEI TEMs have the space to accommodate additional insitu holders for dynamic imaging, diffraction, and tomography applications.

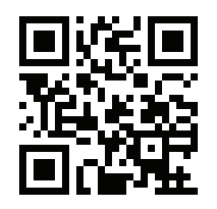

Watch the movie at FEl.com/DiscoverTalos

Explore. Discover. Resolve.

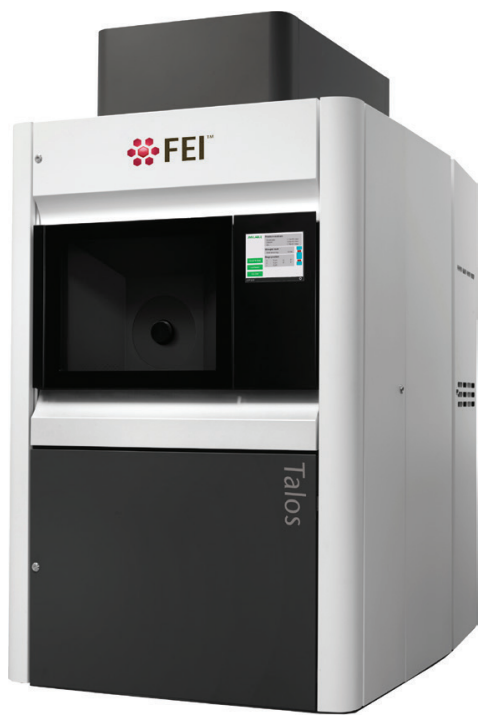




\section{Contents}

About the Cover

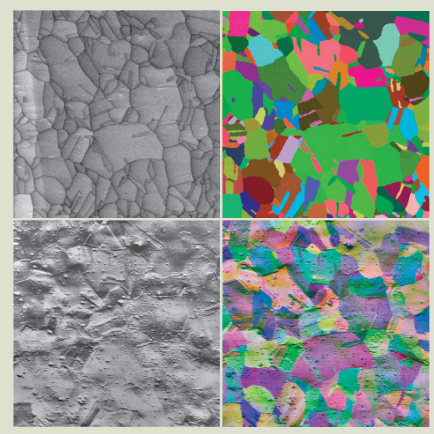

Recrystallized Ni surface imaged with an EBSD detector. Clockwise from top-left: pattern quality image, Euler map, topographical image, and orientation contrast image. Image width $=300 \mu \mathrm{m}$.

See article by Schwarzer and Hjelen.

\section{Microscopy}

\section{Electron Microscopy}

12 Backscattered Electron Imaging with an EBSD Detector Robert A. Schwarzer and Jarle Hjelen

18 A Hybrid Ultramicrotomy-FIB Technique for Preparing Serial Electron Transparent Thin Sections from Particulate Samples Eve L. Berger and Lindsay P. Keller

24 Low-Loss Electron Imaging for Enhanced Surface Detail in the Scanning Electron Microscope: The Contributions of Oliver C. Wells Michael T. Postek and András E. Vladár

\section{Optics}

28 Generalized Fourier Holography Meets Coherent Diffractive Imaging A. J. D’Alfonso, A. V. Martin, A. J. Morgan, P. Wang, H. Sawada, A. I. Kirkland, and L. J. Allen

\section{Meetings}

34 Microscopy \& Microanalysis 2015 in Portland Mark A. Sanders, Program Chair

38 Meeting Report: Microscopy \& Microanalysis 2014 David C. Bell, Program Chair

42 Meeting Report: The 6th Meeting of the International Union of Microbeam Analysis Societies Edward P. Vicenzi, IUMAS-6 Chair

\section{Microscopy Education}

44 Exploring Nanoscience and Scanning Electron Microscopy in K-12 Classrooms

Tonya Coffey, Gabor Zsuppan, and Robert Corbin

\section{Microscopy Pioneers}

48 Pioneers in Optics: Marcello Malpighi and Christian Doppler Michael W. Davidson

\section{Departments}
7 Editorial
8 Carmichael's Concise Review
50 Industry News
52 Product News
54 NetNotes
62 Calendar of Meetings
65 Dear Abbe
66 Index of Advertisers




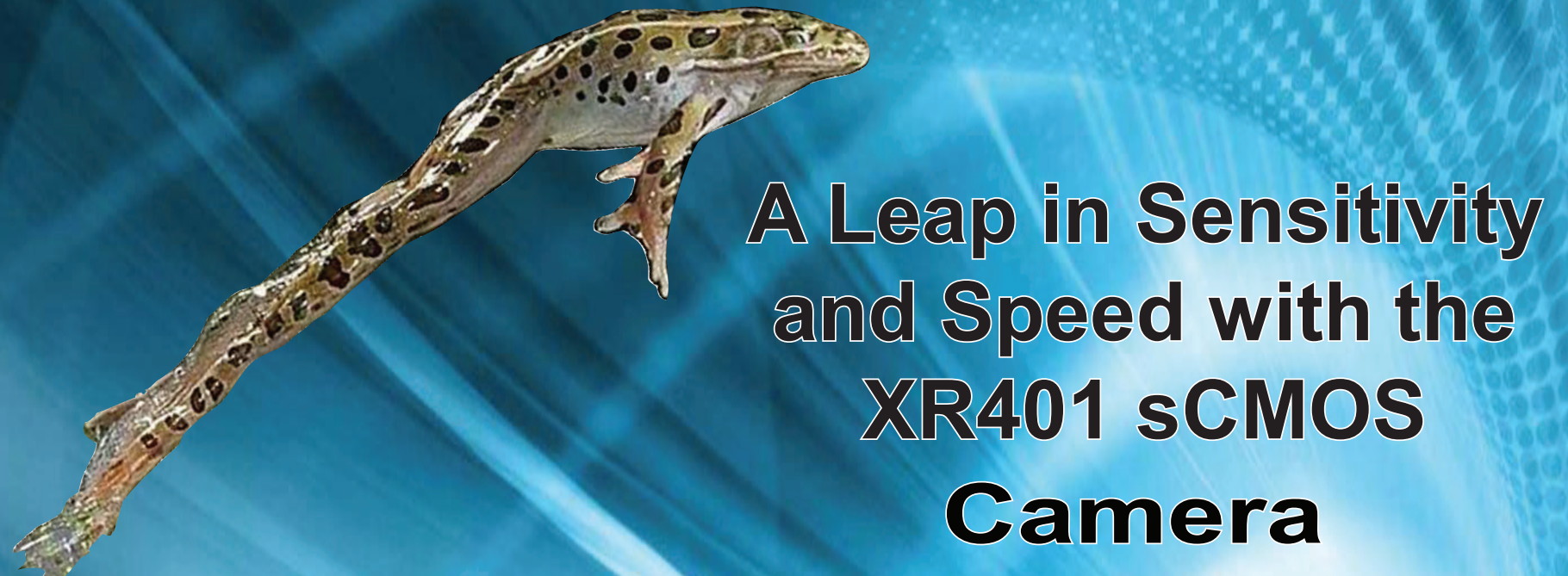

- Cryo TEM

- Low Dose TEM

- Diffraction

- In-Situ TEM

- Extraordinary speed

- Non-Blooming Sensor - $<2$ e/pixel noise

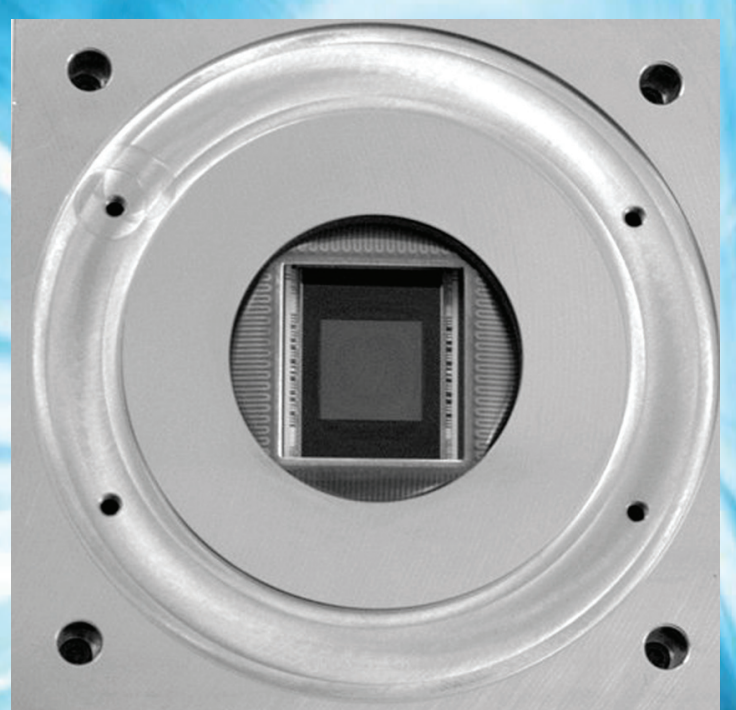

Adenovirus

Dr. Cameron Ackerley

The Hospital for Sick Children

\section{and Speed with the}

XR401 sCMOS

Camera
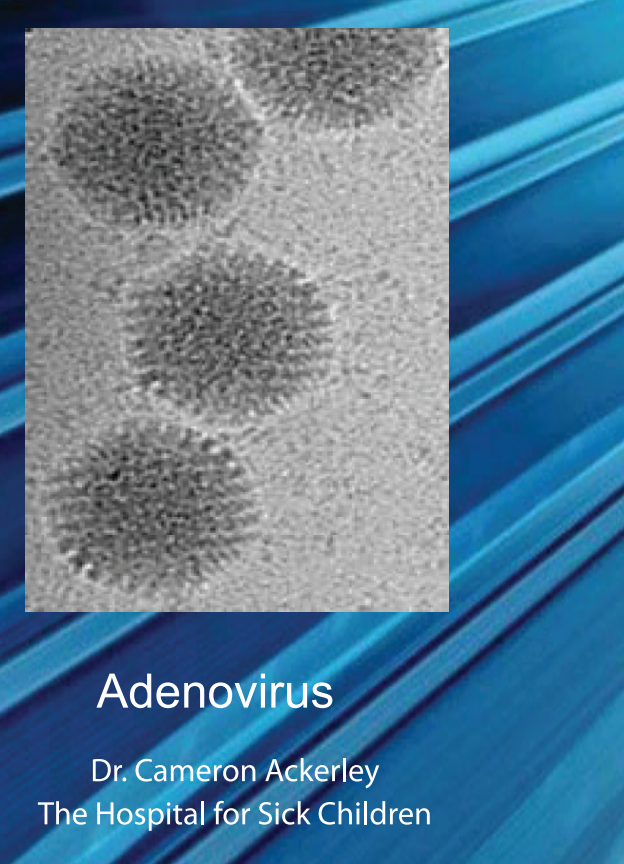

242 West Cummings Park, Woburn, MA 01801

Phone: 978.774.5550 www.amtimaging.com

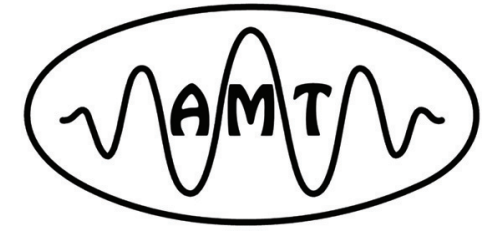

